\title{
Impact of Different Root Conditioning Agents on Periodontally Affected Root Surface: A Scanning Electron Microscope Study
}

\author{
Mohammad Jalaluddin ${ }^{1}$, Pavithra K Ramanna ${ }^{2}$, Dinsha AR Naseema ${ }^{3}$, Mohammad A Alshahrani ${ }^{4}$, Vinutha Kumari ${ }^{5}$, \\ Jenny Atom ${ }^{6}$
}

\begin{abstract}
Aim: The present study aimed to evaluate the effect of various root-conditioning agents on root surfaces that are periodontally affected. Materials and methods: A total of 90 human teeth having single root that were extracted because of chronic periodontitis were chosen. The extracted teeth were cleaned of saliva and blood using a soft-bristled brush and distilled water. The investigational groups were categorized into group I-doxycycline $\mathrm{HCl}$, group II—ethylenediaminetetraacetic acid, and group III—tetracycline $\mathrm{HCl}$. Samples were readied for histological study by scanning electron microscope (SEM). The SEM was used to assess the effectiveness of smear layer removal, amount of patent dentinal tubules out of the totality of dentinal tubules present, and the appreciation of collagen fiber-like structures inside the intertubular area.

Results: The highest efficacy for smear layer removal was seen for group III-tetracycline $\mathrm{HCl}$ samples $(1.80 \pm 0.148)$ followed next by group IIEDTA $(1.36 \pm 0.230)$, and group I-doxycycline $\mathrm{HCl}(1.30 \pm 0.283)$. The highest number of patent dentinal tubules were seen in group IIItetracycline $\mathrm{HCl}(44.50 \pm 0.18)$ followed immediately by group II-EDTA $(38.10 \pm 0.42)$, and group I-doxycycline $\mathrm{HCl}(34.90 \pm 0.23)$. The highest number of appreciation of collagen-like structures was recorded in group III-tetracycline $\mathrm{HCl}(2.64 \pm 0.04)$ followed next by group I—doxycycline $\mathrm{HCl}(1.88 \pm 0.10)$ and group II-EDTA $(1.76 \pm 0.28)$.

Conclusion: The present in vitro study concludes tetracycline $\mathrm{HCl}$ root-conditioning agent to be significantly more efficient in smear layer removal, exposing collagen fibers and amount of patent dentinal tubules than doxycycline $\mathrm{HCl}$ and EDTA.

Clinical significance: The modification of the root surface of human teeth with the use of root conditioning agents leads to enhanced attachment by connective tissue resulting in improved reconstructive periodontal treatment goals.

Keywords: Periodontal diseases, Root conditioning, Scanning electron microscope, Smear layer.

The Journal of Contemporary Dental Practice (2020): 10.5005/jp-journals-10024-2928
\end{abstract}

\section{INTRODUCTION}

Dental calculus and plaque colonization are one among the many periodontal disease determinates. The root surfaces that are diseased do not support cell attachment, and this could be due to adsorption of endotoxins. ${ }^{1}$

Periodontal diseases lead to loss of attachment and exposure of root surface of the teeth to the oral environment. Uncovered cementum shows many changes such as, deposition of plaque and calculus on the surface, unmineralized or hypermineralized surfaces, contamination with endotoxins and cytotoxin, and absence of collagen cross banding, which cause reduction in viability and cell growth of fibroblasts, thus interrupting the new attachment. $^{2}$

The key purpose of periodontal therapy is the re-establishment of periodontium which is lost and alteration in root surfaces that are affected periodontally into a substrate that accepts connective tissue and epithelial cell attachment and adherence biologically. This purpose could be achieved by scaling and root planning and denuded root surfaces treatment with a range of antimicrobial agents and chemicals. ${ }^{3}$ It is not viable to completely disinfect a root surface that is affected by periodontitis solely by mechanical means because the bacterial toxins that are present on root surface do not get eliminated completely and the mechanically disinfected surface will unavoidably get enclosed by a smear layer composed
${ }^{1}$ Department of Periodontics and Oral Implantology, Kalinga Institute of Dental Sciences, KIIT (Deemed to be University), Bhubaneswar, Odisha, India

${ }^{2}$ Department of Prosthodontics, Crown and Bridge and Implantology, Vydehi Institute of Dental Sciences and Research Hospital, Bengaluru, Karnataka, India

${ }^{3}$ Department of Pediatric and Preventive Dentistry, Azeezia College of Dental Sciences and Research, Kollam, Kerala, India

${ }^{4}$ Department of Restorative Dentistry, Ministry of Health, Asser Region, Kingdom of Saudi Arabia

${ }^{5}$ Department of Prosthodontics, Faculty of Dentistry, Majmaah University, Kingdom of Saudi Arabia

${ }^{6}$ Department of Conservative Dentistry and Endodontics, Regional Institute of Medical Sciences, Manipur, India

Corresponding Author: Mohammad Jalaluddin, Department of Periodontics and Oral Implantology, Kalinga Institute of Dental Sciences, KIIT (Deemed to be University), Bhubaneswar, Odisha, India, Phone: +91 9338131843, e-mail: drjalal1979@gmail.com

How to cite this article: Jalaluddin M, Ramanna PK, Naseema DAR, et al. Impact of Different Root Conditioning Agents on Periodontally Affected Root Surface: A Scanning Electron Microscope Study. J Contemp Dent Pract 2020;21(8):863-867.

Source of support: Nil

Conflict of interest: None

() The Author(s). 2020 Open Access This article is distributed under the terms of the Creative Commons Attribution 4.0 International License (https://creativecommons. org/licenses/by-nc/4.0/), which permits unrestricted use, distribution, and non-commercial reproduction in any medium, provided you give appropriate credit to the original author(s) and the source, provide a link to the Creative Commons license, and indicate if changes were made. The Creative Commons Public Domain Dedication waiver (http://creativecommons.org/publicdomain/zero/1.0/) applies to the data made available in this article, unless otherwise stated. 
of dental calculus remnants, subgingival plaque, and contaminated cementum. The smear layer acts as a barrier between root surfaces and periodontal tissues, physically, and, as a result, inhibits the new attachment formation. ${ }^{4}$

In order to promote new attachment, a variety of chemical root-conditioning agents (phosphoric acid, citric acid, doxycycline hydrochloride $(\mathrm{HCl})$, tetracycline $\mathrm{HCl}$, minocycline $\mathrm{HCl}$, ethylenediaminetetraacetic acid (EDTA), fibronectin, sodium deoxycholate, hydrochloric acid, Cohn's factor, etc.) and physical methods (laser) have been used subsequent to root instrumentation. These agents uncover proteins bound to cementum and dentin collagen and have been found to wash away the remaining toxins adhering the diseased root surfaces. ${ }^{5}$ Therefore, this study was performed with an aim to evaluate the efficacy of three rootconditioning agents on root surfaces that are periodontally involved.

\section{Materials and Methods}

The present in vitro study was conducted in the Department of Periodontics, Kalinga Institute of Dental Sciences, Bhubaneswar, India. Ninety single-rooted human teeth indicated for extraction due to chronic periodontitis were collected for the present study.

\section{Criteria for Selection of the Teeth}

No records of scaling, root planing, and prophylaxis in the past 6 months; no records of swelling or acute pain requiring their extraction; loss of proximal attachment by $5 \mathrm{~mm}$ or more; bleeding on gentle probing; and lack of proximal surface caries.

\section{Preparation of the Specimen}

The extracted teeth were cleaned of saliva and blood using a softbristled brush and distilled water. After cleaning, the root surfaces were carefully root planed using a Gracey curette (no. 1/2). A finishing bur (no. 102R) at a speed of about 400,000 rpm in high-speed hand piece was later used to eliminate the cementum and attain an even and hard surface like a glass. Experimental surface was obtained by removing the crown of each tooth at the level of cementoenamel junction (CEJ), and then a portion of root $5 \mathrm{~mm}$ from the CEJ was selected. A double-sided diamond disk mounted in a slow-speed hand piece under continuous and plentiful water irrigation was used to slice the specimen into two equal longitudinal halves along the pulp chamber. A straight bur was used to flatten the pulpal side, and a straight groove was made on the horizontal surface for recognition.

\section{Preparation and Application of Root-conditioning Agents}

Based on the type of root-conditioning agent used, the experimental groups were categorized into groups I, II, and III with 30 samples in each group.

\section{Group I-Doxycycline $\mathrm{HCl}$}

A $100 \mathrm{mg} / \mathrm{mL}$ solution was prepared by mixing doxycycline $\mathrm{HCl}$ powder of $100 \mathrm{mg}$ in $1 \mathrm{~mL}$ of sterile water. A pH meter showed a $\mathrm{pH}$ of 2.2 for this solution. Completely soaked cotton pellets with doxycycline $\mathrm{HCl}$ solution were placed on the root surfaces for the total time of 5 minutes to treat them. The soaked cotton pellets were replaced every 30 seconds.

\section{Group II-Ethylenediaminetetraacetic Acid}

A $15 \%$ EDTA solution was prepared by adding $4.25 \mathrm{~g}$ of the EDTA's disodium salt to a mix of $25 \mathrm{~mL}$ distilled $\mathrm{H}_{2} \mathrm{O}$ with 5 normality $\mathrm{NaOH}$ of $2.31 \mathrm{~mL}$. The $\mathrm{pH}$ meter showed a pH of 7.5. Completely soaked cotton pellets with EDTA solution were placed on the root surfaces for the total time of 5 minutes to treat them. The soaked cotton pellets were replaced every 30 seconds.

\section{Group III-Tetracycline $\mathrm{HCl}$}

A tetracycline solution of $\mathrm{pH} 1.3$ was obtained by dissolving a tetracycline $\mathrm{HCl}$ capsule of $500 \mathrm{mg}$ in sterile distilled $\mathrm{H}_{2} \mathrm{O}$ of $5 \mathrm{~mL}$ quantity with constant stirring for 10 minutes. Cotton pellets that were completely drenched with tetracycline $\mathrm{HCl}$ solution were used to treat the root surfaces for 5 minutes, and these pellets were changed every 30 seconds.

\section{Specimen Preparation for SEM Study}

Once the root surfaces were treated, they were fixed at $40^{\circ} \mathrm{C}$ for 24 hours in $2.5 \%$ glutaraldehyde in phosphate buffer of $7.3 \mathrm{pH}$. All the samples were washed in phosphate buffer thrice for 10 minutes each, after being fixed in osmium tetroxide in $1.5 \%$ phosphate buffer for 2 hours and were again washed thrice in phosphate buffer. The samples were later dried out in ethanol solutions of graded series for 10 minutes each. After rinsing in absolute ethanol for 2 additional 10 minutes duration, the samples were dehydrated during the entire night in a silica gel desiccator jar. SEM stubs with silver paint were used to mount the samples. All samples were observed under a scanning electron microscope (SEM), and analysis was done in KIDS, Bhubaneswar.

\section{SEM Analysis}

The samples were observed at 1,500× magnification of a SEM (Figs 1 to 3). The micrographs were recorded and were assessed for

\section{- Efficacy of smear layer removal}

Smear layer removal was assessed by Madison and Hokett ${ }^{6}$ provided 1997 scale in accordance with the following criteria $0=$ No removal or no apparent effect on the smear layer

$1=$ Greater than no effect, but less than one-half removal

$2=$ Approximately one-half removal of the smear layer

$3=$ Greater than one-half but less than complete removal

$4=$ Complete removal of the smear layer with clean and open dentinal tubules.

- Number of dentinal tubules that are patent of the total number of tubules that are present.

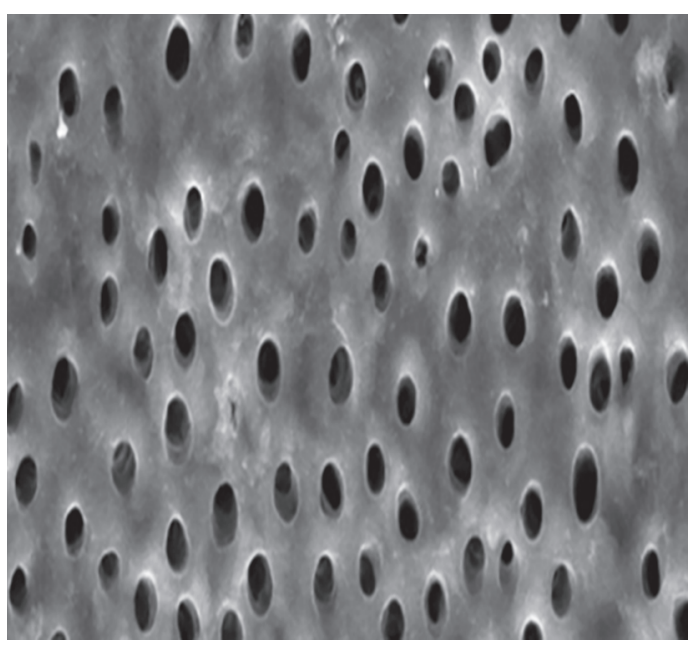

Fig. 1: Doxycycline $\mathrm{HCl}$ root conditioning agents as analyzed by SEM 


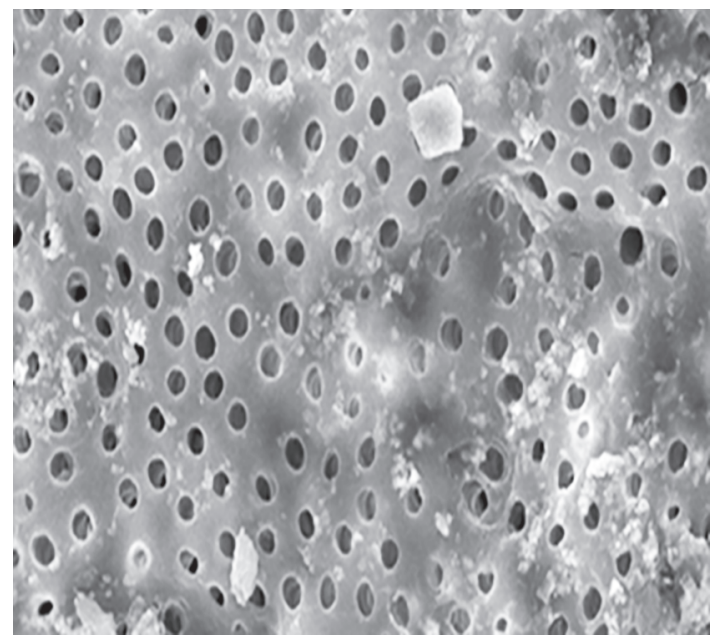

Fig. 2: EDTA root conditioning agents as analyzed by SEM

Table 1: Mean of efficacy in smear layer removal in all the three groups

\begin{tabular}{lll}
\hline Groups & $n$ & Mean \pm Std. deviation \\
\hline Group I-doxycycline HCl & 30 & $1.30 \pm 0.283$ \\
Group II-EDTA & 30 & $1.36 \pm 0.230$ \\
Group III-tetracycline HCl & 30 & $1.80 \pm 0.148$ \\
\hline
\end{tabular}

Table 3: Mean number of patent dentinal tubules in all the three groups

\begin{tabular}{lll}
\hline Groups & $n$ & Mean \pm Std. deviation \\
\hline Group I-doxycycline HCl & 30 & $34.90 \pm 0.23$ \\
Group II-EDTA & 30 & $38.10 \pm 0.42$ \\
Group III-tetracycline HCl & 30 & $44.50 \pm 0.18$ \\
\hline
\end{tabular}

- The appreciation of collagen fiber-like structures present in the intertubular area was assessed.

\section{Statistical Analysis}

A Statistical Package for Social Sciences (SPSS) version 20 (SPSS Inc.Chicago, IL, USA) was used to analyze the collected data. The arithmetic mean and the standard deviations were used to perform the analysis. Comparison between groups was done using Student's unpaired $t$ test. A $p$ value of $<0.05$ was considered as statistically significant.

\section{Results}

The mean of efficacy in removal of smear layer is as shown in Table 1 for all the three groups. The highest efficacy for smear layer removal was seen for group III-tetracycline $\mathrm{HCl}$ samples $(1.80 \pm$ $0.148)$ followed next by group II-EDTA $(1.36 \pm 0.230)$ and group I-doxycycline $\mathrm{HCl}(1.30 \pm 0.283)$.

On intergroup comparison of the mean efficacy of smear layer removal, a statistically significant difference ( $p$ value $<0.001$ ) was noted between groups I and III and groups II and III as displayed in Table 2.

The mean number of dentinal tubules that are patent is as shown in Table 3 for all the three groups. The highest number of patent dentinal tubules were seen in group III-tetracycline $\mathrm{HCl}$ $(44.50 \pm 0.18)$, followed immediately by group II-EDTA (38.10 \pm $0.42)$, and group I-doxycycline $\mathrm{HCl}(34.90 \pm 0.23)$.

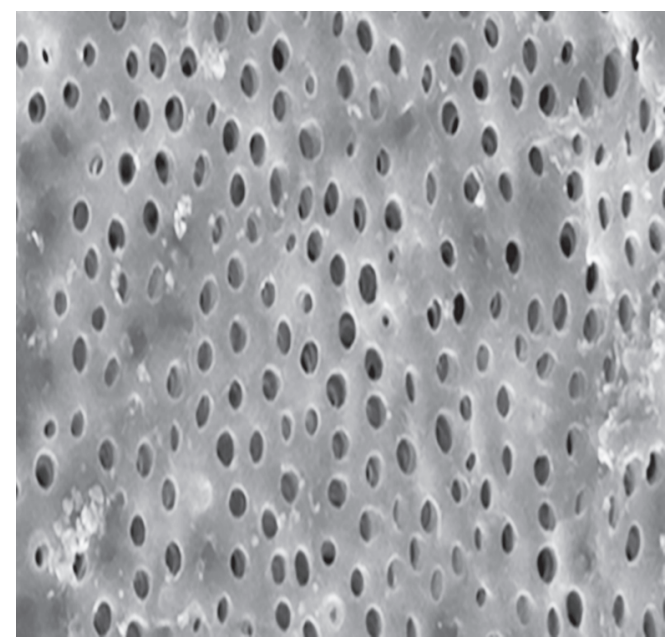

Fig. 3: Tetracycline $\mathrm{HCl}$ root conditioning agents as analyzed by SEM

Table 2: Comparison of mean of smear layer removal in all the three groups

\begin{tabular}{lllll}
\hline & & \multicolumn{3}{c}{ Difference between groups } \\
\cline { 3 - 5 } Groups & $\begin{array}{l}\text { Mean } \pm \text { Std. } \\
\text { deviation }\end{array}$ & $\begin{array}{l}\text { Group } \\
\text { compared }\end{array}$ & $T$ & p value \\
\hline $\begin{array}{l}\text { Group I- } \\
\text { doxycycline HCl }\end{array}$ & $1.30 \pm 0.283$ & $\begin{array}{l}\text { Group I vs } \\
\text { group II }\end{array}$ & 24.224 & 0.12 \\
Group II-EDTA & $1.36 \pm 0.230$ & $\begin{array}{l}\text { Group I vs } \\
\text { group III }\end{array}$ & 21.00 & $0.001^{*}$ \\
Group III- & $1.80 \pm 0.148$ & $\begin{array}{l}\text { Group II vs } \\
\text { group III }\end{array}$ & 22.848 & $0.001^{*}$ \\
tetracycline HCl & & &
\end{tabular}

*Highly significant

Table 4: Comparison of mean number of patent dentinal tubules in all the three groups

\begin{tabular}{lllll}
\hline & & \multicolumn{3}{c}{ Difference between groups } \\
\cline { 3 - 5 } Groups & $\begin{array}{l}\text { Mean } \pm \text { Std. } \\
\text { deviation }\end{array}$ & $\begin{array}{l}\text { Group } \\
\text { compared }\end{array}$ & $T$ & p value \\
\hline $\begin{array}{l}\text { Group I_doxy- } \\
\text { cycline HCl }\end{array}$ & $34.90 \pm 0.23$ & $\begin{array}{l}\text { Group I vs } \\
\text { group II }\end{array}$ & 19.021 & 0.82 \\
$\begin{array}{l}\text { Group II-EDTA } \\
\text { Group II vs }\end{array}$ & 20.224 & $0.001^{*}$ \\
$\begin{array}{l}\text { Group III-tetra- } \\
\text { cycline HCl }\end{array}$ & $44.50 \pm 0.10 \pm 0.42$ & $\begin{array}{l}\text { Group III } \\
\text { Group II vs } \\
\text { group III }\end{array}$ & 19.890 & 0.06 \\
\hline
\end{tabular}

*Highly significant

The intergroup comparison of presence of mean number of patent dentinal tubules in all the three groups were found to be statistically significant ( $p$ value $<0.001$ ) between groups I and III as displayed in Table 4.

Table 5 shows the mean appreciation of collagen-like structures in all the three groups. The highest number of appreciation of collagen-like structures was recorded in group III-tetracycline $\mathrm{HCl}(2.64 \pm 0.04)$, followed next by group I-doxycycline $\mathrm{HCl}(1.88$ $\pm 0.10)$, and group II-EDTA (1.76 \pm 0.28$)$.

A statistically significant difference ( $p$ value $<0.001$ ) was found between groups I and II, Groups I and III and groups II and III for the mean appreciation of collagen-like structures on inter-group comparison and is as displayed in Table 6. 
Table 5: Mean appreciation of collagen-like structures in all the three groups

\begin{tabular}{lll}
\hline Groups & $n$ & Mean \pm Std. deviation \\
\hline Group I-doxycycline HCl & 30 & $1.88 \pm 0.10$ \\
Group II-EDTA & 30 & $1.76 \pm 0.28$ \\
Group III-tetracycline HCl & 30 & $2.64 \pm 0.04$ \\
\hline
\end{tabular}

The inference of the present study indicates that the tetracycline $\mathrm{HCl}$ group root-conditioning agent showed significantly more efficient in removing the smear layer, exposing number of patent dentinal tubules and collagen fibers than EDTA and doxycycline $\mathrm{HCl}$ groups, respectively.

\section{Discussion}

The acidic solutions that are applied topically and used for root surface conditioning have been shown to eliminate smear layer of root instrumentation and residual contaminants on root surface. Root surface demineralization by root-conditioning agents have been associated with exposure and expansion of the dentinal tubules with dentin collagen exposure, thus providing an environment that aids in migration and division of cells involved in healing of periodontal wounds ensuing in increased attachment of connective tissue cells on to the root surfaces., ${ }^{7,8}$

In the present study, each root conditioner was applied passively using cotton pellets that were completely soaked with the conditioning agent for a total period of 5 minutes with the cotton pellet being changed every 30 seconds. The "Passive Burnishing Technique" for root conditioner application has been chosen over burnishing technique because the method of burnishing may result in development of smear layer that completely or partially occludes the dentinal tubule openings. The cotton pellets were changed every 30 seconds to maintain a continuous stable dose of application of root conditioner. This procedure has been suggested to boost a mechanical/chemical act that would chemically loosen surface debris and inorganic material, thus exposing subsurface dentin to demineralizing role of fresh acid. ${ }^{9}$

In this study, highest smear removal was seen in tetracycline $\mathrm{HCl}$ group followed next by EDTA and doxycycline $\mathrm{HCl}$ group. Our findings are unlike the findings of Mythili and Ahamed, ${ }^{5}$ Isik et al., ${ }^{10}$ and Lafferty et al. ${ }^{11}$ who found near-total and equivalent efficacy of EDTA and tetracycline $\mathrm{HCl}$ in smear layer removal. Tetracycline $\mathrm{HCl}$ showed an increase in patency and number of dentinal tubules as compared to EDTA. The $\mathrm{pH}$ of tetracycline $\mathrm{HCl}(\mathrm{pH}=2.2)$ was lower than ph of EDTA ( $\mathrm{pH}=4.7)$ and this may explain the dissimilarity, so an increased concentration of EDTA may be needed to obtain the equivalent results.

The mean total number of tubules was found to be highest in tetracycline $\mathrm{HCl}$-treated samples followed next by EDTAtreated samples and doxycycline. The findings by Lafferty et al. ${ }^{11}$ showed comparable surface characteristics with tetracycline $\mathrm{HCl}$ conditioning when applied on human root surfaces affected by periodontal diseases. This could be due to more acidic $\mathrm{pH}$ of tetracycline $\mathrm{HCl}(\mathrm{pH} 1.6)$ compared to less acidic $\mathrm{pH}$ of doxycycline (pH 2.2) which causes exposure of comparable and substantial number of dentinal tubules compared to the other agents. These findings are similar to those obtained by Shetty et al. ${ }^{12}$ and Madison et al. ${ }^{6}$

The highest number of patent tubules was seen in tetracyclinetreated samples than EDTA and doxycycline. Of the three agents
Table 6: Comparison of mean appreciation of collagen-like structures in all the three groups

\begin{tabular}{|c|c|c|c|c|}
\hline \multirow[b]{2}{*}{ Groups } & \multirow[b]{2}{*}{$\begin{array}{l}\text { Mean } \pm \text { Std } \\
\text { deviation }\end{array}$} & \multicolumn{3}{|c|}{ Difference between groups } \\
\hline & & $\begin{array}{l}\text { Group } \\
\text { compared }\end{array}$ & $T$ & $p$ value \\
\hline $\begin{array}{l}\text { Group I- } \\
\text { doxycycline } \\
\mathrm{HCl}\end{array}$ & $1.88 \pm 0.10$ & $\begin{array}{l}\text { Group I vs } \\
\text { group II }\end{array}$ & 22.168 & $0.02^{*}$ \\
\hline $\begin{array}{l}\text { Group II- } \\
\text { EDTA }\end{array}$ & $1.76 \pm 0.28$ & $\begin{array}{l}\text { Group I vs } \\
\text { group III }\end{array}$ & 19.880 & $0.001^{*}$ \\
\hline $\begin{array}{l}\text { Group III- } \\
\text { tetracycline } \\
\mathrm{HCl}\end{array}$ & $2.64 \pm 0.04$ & $\begin{array}{l}\text { Group II vs } \\
\text { group III }\end{array}$ & 21.430 & $0.001^{*}$ \\
\hline
\end{tabular}

*Highly significant

used, doxycycline-treated samples had the least number of patent tubules. These findings are in accordance with previous studies by Madison et al. ${ }^{6}$ and Ashok et al. ${ }^{13}$ This finding is unlike the findings by Garg et al. ${ }^{14}$ This could be ascribed to the fact that tetracycline have an increased substantivity on dentine surface.

The tetracycline use has been related to improve adhesion between dentin and glycoprotein; stimulation, adhesion, and increased number of fibroblasts; inhibition of osteoclast and neutrophil function; anticollagenase activity; and efficacious substantively. In our study, tetracycline $\mathrm{HCl}$-treated samples demonstrated favorable results for all the parameters that were evaluated. ${ }^{15}$

In this study, the effectiveness of root-conditioning agents was assessed using a histological method of evaluation-the SEM. As all the analysis was dependent on the SEM, the present study used improved resolution, enhanced magnification along the interface, and better field depth. The possible usefulness of tetracycline on dentine has been demonstrated by an in vitro study of Terranova et al. ${ }^{3}$ Numerous studies including tetracycline have demonstrated its several effective properties such as superior anti-collagenase activity, improved growth and attachment of gingival fibroblasts, increased substantivity, and inhibition of parathyroid hormone that leads to bone resorption. A significant difference in mean number of patent dentinal tubules has been recorded for all three experimental groups.

In the present study, all the three experimental groups showed root-conditioning agents to be helpful in smear layer removal, dentinal tubule exposure, and appreciation of collagen fiber-like structures in vitro. However, the result of this study is restricted to physical finding of changes in root surface and does not demonstrate differences in an in vivo condition that may originate from the physiologic effect of these root-conditioning agents, and this is the limitation of the present study. Variables such as disease condition of the dentine specimens, type of demineralizing agent, or a combination of such variables accounts for dissimilarity between present study results and results of other studies. Additional studies have to be conducted in the future after considering other confounding factors.

\section{ConCLUSION}

The present in vitro study concludes tetracycline $\mathrm{HCl}$ rootconditioning agent to be significantly more efficient in smear layer 
removal, exposing collagen fibers, and amount of patent dentinal tubules than doxycycline $\mathrm{HCl}$ and EDTA.

\section{References}

1. Rohanizadeh R, Legeros RZ. Ultrastructural study of calculus-enamel and calculus-root interfaces. Arch Oral Biol 2005;50(1):89-96. DOI: 10.1016/j.archoralbio.2004.07.001.

2. Chahal GS, Chhina K, Chhabra V, et al. Effect of citric acid, tetracycline, and doxycycline on instrumented periodontally involved root surfaces: a SEM study. J Indian Soc Periodontol 2014;18(1):32-37. DOI: 10.4103/0972-124X.128196.

3. Terranova VP, Franzetti LC, Hic S, et al. A biochemical approach to periodontal regeneration: tetracycline treatment of dentin promotes fibroblast adhesion and growth. J Periodontal Res 1986;21(4):330-337. DOI: 10.1111/j.1600-0765.1986.tb01467.x.

4. Nanda T, Jain S, Kaur H, et al. Root conditioning in periodontologyrevisited. J Nat Sci Biol Med 2014;5(2):356-358. DOI: 10.4103/09769668.136183

5. Mythili R, Ahamed BR. Efficacy of tetracycline hydrochloride and doxycycline hydrochloride as a root conditioner-a scanning electron microscopic study. J Indian Soc Periodontol 2006;10: 227-232.

6. Madison JG, Hokett SD. The effects of different tetracyclines on the dentin root surface of instrumented, periodontally involved human teeth: a comparative scanning electron microscope study. J Periodontol 1997;68(8):739-745. DOI: 10.1902/jop.1997.68. 8.739.

7. Leite FR, Sampaio JE, Zandim DL, et al. Influence of root-surface conditioning with acid and chelating agents on clot stabilization. Quintessence Int 2010;41(4):341-349.
8. Nanda T, Jain S, Kapoor D, et al. Comparison of the efficacy of ethylenediaminetetraacetic acid and tetracycline hydrochloride as root conditioning agents: an in vitro study. J Int Clin Dent Res Organ 2012;4(1):2-8. DOI: 10.4103/2231-0754.131368.

9. Nathalia GA, Maria LR, Fabiana $H$, et al. Comparison among four commonly used demineralizing agents for root conditioning. A scanning electron microscopy. J Appl Oral Sci 2011;19(5):469-475. DOI: 10.1590/S1678-77572011000500006.

10. Isik AG, Tarim B, Hafez AA, et al. A comparative scanning electron microscopic study on the characteristics of demineralized dentin root surface using different tetracycline $\mathrm{HCl}$ concentrations and application times. J Periodontol 2000;71(2):219-225. DOI: 10.1902/jop.2000.71.2.219.

11. Lafferty TA, Gher ME, Gray JL. Comparative SEM study on the effect of acid etching with tetracycline $\mathrm{HCl}$ or citric acid on instrumented periodontally-involved human root surfaces. J Periodontol 1993;64(8):689-693. DOI: 10.1902/jop.1993.64.8.689.

12. Shetty B, Dinesh A, Seshan $\mathrm{H}$. The comparative effects of tetracyclines and citric acid on dentin root surface of periodontally involved human teeth: a scanning electron microscope study. J Indian Soc Periodontol 2008;12(1):8-15. DOI: 10.4103/0972-124X.44090.

13. Ashok KP, Shobha PM. A comparative scanning electron microscope study on the effect of acid etching with citric acid, tetracycline hydrochloride and EDTA on instrumented, periodontally involved root surfaces. Indian J Stomatol 2010;1:61-66.

14. Garg J, Maurya R, Gupta A, et al. An in vitro scanning electron microscope study to evaluate the efficacy of various root conditioning agents. J Indian Soc Periodontol 2015;19(5):520-524. DOI: 10.4103/0972-124X.167168.

15. Silva AC, Moura CC, Ferreira JA, et al. Biological effects of a root conditioning treatment on periodontally affected teeth-an in vitro analysis. Braz Dent J 2016;27(2):160-168. DOI: 10.1590/01036440201600427. 